\title{
Voegelin y Kelsen sobre la representación política ${ }^{1}$
}

Voegelin and Kelsen about the political representation

\section{BRUNO VENDRAMIN}

\begin{abstract}
Abogado, Facultad de Derecho, Universidad Nacional de Córdoba. Especialista en Derecho Constitucional, Universidad de Salamanca. Correo electrónico: brunovendraminn@gmail.com
\end{abstract}

\section{Resumen}

En la década del 50 y en pleno contexto de la posguerra, Eric Voegelin y Hans Kelsen mantuvieron un intenso debate sobre la ciencia política $\mathrm{y}$, en particular, sobre el concepto de representación. A raíz de la publicación de La nueva ciencia de la política de Voegelin en 1952, Kelsen escribió un largo y exhaustivo artículo sobre el libro que permaneció inédito por varias décadas, y que, en castellano, se publicó hace algunos años bajo el título ¿Una nueva ciencia de la política? Réplica a Eric Voegelin. Con concepciones disímiles acerca de la representación, Voegelin cree en un tipo de representación que denomina existencial y que va más allá de las instituciones democráticas y del Parlamento, mientras Kelsen rechaza esta tesis, sosteniendo que es el Parlamento el mejor lugar para la representación política.

\section{Abstract}

During postwar's 1950's, Eric Voegelin and Hans Kelsen debated intensely on political science in general, and on the concept of representation in particular. As a result of the publication of Voegelin's The new science of politics in 1952, Kelsen dedicated a long and thorough article about the book, that remained unedited for decades, until A new science of politics? Response to Eric Voegelin was published a few years ago, in Spanish. With different approaches on the idea of representation, Voegelin stands for a type of representation whom we calls existential, that goes beyond democratic institutions and Parliament, while Kelsen rejects this thesis, arguing that Parliament is indeed the best place for polítical representation.

\footnotetext{
${ }^{1}$ Una primera versión de este artículo fue presentado como ponencia en el XIII Congreso Nacional de Derecho Político, septiembre de 2016, en la Facultad de Derecho de la Universidad Nacional de Rosario.
} 
Perspectivas Revista de Ciencias Sociales - ISSN 2525-1112|Año 3 No. 5 Enero-Junio 2018, pp. 131-146

Palabras clave

Eric Voegelin - Hans Kelsen Representación política Positivismo
Keywords

Eric Voegelin - Hans Kelsen Political representation - Positivism

\section{Introducción}

En la década del 50, Eric Voegelin (1901 - 1985) y Hans Kelsen (1881 1973) mantuvieron un intenso y rico debate sobre la ciencia política y, en particular, sobre el concepto de representación. A raíz de la publicación de $L a$ nueva ciencia de la política de Voegelin en 1952, Kelsen escribió un largo y exhaustivo artículo sobre el libro que permaneció inédito por varias décadas, y que, en castellano, se publicó hace algunos años bajo el título ¿Una nueva ciencia de la política? Réplica a Eric Voegelin. En este contexto, la representación se colocó en el centro de la interpretación de los dos pensadores. No obstante, el marco de la discusión intelectual no se limitó a ella. Por el contrario, disparó otros problemas filosófico-políticos y jurídicos: la manera que tiene el investigador de hacer ciencia y la discusión sobre el positivismo (Voegelin asumió un compromiso fuertemente antipositivista y Kelsen fue uno de los máximos exponentes del positivismo), el rol de la religión y de la metafísica, el gnosticismo, el origen de la ley, el problema de la democracia, etc.

En el presente escrito, examino el debate acerca de la representación política sostenido por Voegelin y Kelsen. Estimo que es de fundamental importancia re-pensar dicho concepto, por lo que para esto la producción filosófica de los dos autores se convierte en una herramienta valiosísima. La obra de los dos filósofos no ha perdido vigencia alguna. Además, pocas categorías políticas son tan urgentes de análisis en la ciencia política y en el derecho contemporáneo-amén de que constituye una problemática histórica y que se remonta a los inicios mismos del filosofar político, desde Platón en adelante.

En primer lugar, reconstruyo brevemente el contexto histórico de los autores, porque no se puede comprender acabadamente la querella intelectual de Voegelin y Kelsen sin situarlos en su época, y además porque las ideas son hijas de su propio tiempo. Luego, analizo la representación en la obra de Voegelin, para después proseguir con la crítica que formuló Kelsen y poder ver qué entiende éste por representación. Por último, delibero de manera crítica alrededor de ambas propuestas con el objetivo de extraer y plantear algunas tesis para pensar la representación política en el presente.

\section{Contexto histórico}

Voegelin y Kelsen vivieron una misma época cultural, histórica y política. El primero nacido en Colonia, Alemania, y el segundo en Praga, los dos estudian y ocupan cátedras en la Facultad de Derecho de la Universidad de Viena. De hecho, Voegelin se doctoró en Ciencia Política bajo la dirección de Kelsen y Othmar Spann en esta Universidad, con la tesis Wechselwirkung und 
Gezweiung (1922), una comparación de las categorías sociológicas de Georg Simmel con las de Spann. Kelsen, en la década del 20, redacta la Constitución austriaca y forma parte del Tribunal Constitucional austriaco. Testigos centrales del surgimiento del fascismo, el comunismo y el nacionalsocialismo, estos movimientos políticos determinan sus vidas y se convierten en los objetos centrales de su quehacer filosófico. El nacionalsocialismo provoca el exilio de ambos (Kelsen abandona su cátedra en la Universidad de Colonia en 1933 y Voegelin escapa a Suiza en 1938). Los dos fueron acérrimos enemigos de los totalitarismos pero lo hicieron desde ángulos opuestos y con intereses distintos (el primero lo hizo desde una perspectiva conservadora y antiliberal; Kelsen lo hizo desde la defensa de la democracia constitucional y la socialdemocracia).

Posteriormente, en la década del 40 , se instalan en Estados Unidos: Voegelin se establece en la Universidad Estatal de Louisiana y luego en Stanford, y Kelsen lo hace primero en Harvard y luego en la Universidad de California, Berkeley. Por el exilio y otras circunstancias biográficas, manejan con habilidad la lengua inglesa y escriben sendos libros en inglés. En el caso que nos toca, La nueva ciencia de la política y la crítica de Kelsen están escritas en inglés.

En 1952, Voegelin publica La nueva ciencia de la política. El origen del libro son seis disertaciones que dictó en el invierno de 1951 en la Universidad de Chicago ${ }^{2}$. Un tiempo después de publicado, y luego de que el libro consiguió un éxito considerable y posicionó definitivamente a Voegelin entre los cientistas políticos más respetados, entre 1953 y 1954, Kelsen estudia el texto y escribe su crítica: ¿Una nueva ciencia de la política? Réplica a Eric Voegelin. Kelsen nunca publicó el manuscrito. En castellano, se conoció recién en el año 2006. Por esta razón (aunque no sólo por ésta), en los países de habla hispana ${ }^{3}$ el debate Voegelin-Kelsen no ha gozado de la suficiente atención, como tampoco abundan los estudios críticos, como sí ha ocurrido en la tradición anglosajona y también en Alemania.

\section{Voegelin y la representación}

Desde el inicio de La nueva ciencia de la política (en adelante, NCP), Voegelin declara que el problema central de una teoría de la política es la representación. Convencionalmente, en la teoría política, entendemos a las instituciones representativas como el Parlamento y algunos otros órganos del Estado. Voegelin denomina a la representación constitucional-parlamentaria como representación elemental. Se pregunta: para el teórico de la política, ¿qué aporta la representación elemental? ¿Hay algún otro aspecto de la representación que ha permanecido en las sombras y no se le ha otorgado la debida atención?

\footnotetext{
2 El título original de las conferencias era Verdad y Representación, mas Voegelin al ampliar el material para la publicación como libro cambió el título. Esta aclaración no es irrelevante, ya que, como se verá, la ciencia política para Voegelin tiene que resolver, fundamentalmente, el problema de la verdad y el problema de la representación.

${ }^{3}$ A más de que casi no existen estudios críticos ni artículos sobre el debate entre Voegelin y Kelsen, sobre la obra del primero existe muy poca bibliografía en español porque la mayoría de los textos en inglés permanece sin traducción. Uno de los estudios más importante en español es el de Carlos Casanova. Véase CASANOVA, C. (1997). Verdad escatológica y acción intramundana. La teoría política de Eric Voegelin. Navarra: Eunsa.
} 
¿Qué valor epistemológico tiene para la ciencia política quedarse sólo con este aspecto de la representación, es decir, el jurídico-formal? Sin duda que la representación elemental aporta elementos teóricos relevantes para pensar la política, pero no se puede creer que allí se agota el problema: "El tipo elemental de instituciones representativas no agota el problema de la representación" (Voegelin, 2006: 50). La estrategia del filósofo alemán es desplegar un concepto de representación distinto a lo que "convencionalmente" se entiende como instituciones representativas: para esto introduce la separación entre representación elemental y representación existencial. Así pues, su análisis "procederá a una explicación de los símbolos por medio de las cuales las sociedades políticas se interpretan a sí mismas como representantes de una verdad trascendente." (Voegelin, 2006: 13).

Como, según el filósofo alemán, las sociedades se autointerpretan a sí mismas mediante símbolos, necesitan de otro tipo de representación. Así, para explicitar la representación en sentido existencial, Voegelin desarrolla el concepto de articulación: una sociedad articulada es una unidad de poder que tiene una organización interna que permite a alguno de sus miembros -el soberano, el magistrado, el príncipe- "contar con un grado habitual de obediencia a sus órdenes" (Voegelin, 2006: 52). Como resultado de la articulación social, los gobernantes actúan por la sociedad y las decisiones se imputan a la sociedad misma. Los individuos se unen como sociedad para la acción mediante un representante, formando una unidad. "La articulación, entonces, es la condición de la representación." (Voegelin, 2006: 57). En la época en la que escribe, el ejemplo paradigmático que encuentra es la URSS: "El gobierno soviético representa a la sociedad soviética como sociedad política apta para actuar en la historia." (Voegelin, 2006: 51).

Voegelin rastrea en la historia medieval cómo las sociedades han producido esta articulación, y para esto toma el caso de Inglaterra. Todas las unidades de poder que existían allí (Municipios, Condados, Ciudades) se fueron articulando para unificarse en cabeza del Rey y el Parlamento, y luego estos devinieron cabeza y miembro de un mismo cuerpo. Del ciudadano al Rey, la sociedad se va articulando para constituir una unidad compacta. Escribe Voegelin que "cuando la articulación se expande a toda la sociedad, también el representante se expande hasta que se alcanza el límite en el que la pertenencia a la sociedad se articula políticamente hasta el último individuo, y, en forma correspondiente, la sociedad se vuelve representativa de sí misma." (Voegelin, 2006: 56).

Voegelin observa que la articulación de los estados occidentales se produjo con la consolidación de los reinos nacionales, a mediados del siglo XV. Sirviéndose del discurso de Enrique VIII ante el Parlamento en 1543 (Enrique dijo que el Rey y el Parlamento constituían un solo cuerpo político y que cualquier ofensa o perjuicio contra los miembros de la Cámara debe ser considerada como cometida contra todo el reino), la obra de Sir John Fortescue (1394 - 1479) -que creía que la sociedad sólo se articula con el establecimiento de un rex y que fue el creador de la categoría intencio populi (la sustancia mística intangible de la sociedad)- y de relatos mitológicos medievales (como la History of the Lombards 
de Paulus Diaconus, en la que se relata el deseo de los lombardos de darse un rey para afrontar las guerras), el pensador alemán encuentra que las sociedades sólo cobran existencia política cuando se articulan de manera unificada y se dan un único representante. Pero es en la obra de Maurice Hauriou donde más apoya Voegelin su propuesta de representación existencial. En efecto, para el institucionalismo de Hauriou, la tarea del representante es la creación de una nación unificada, convirtiendo la multiplicidad reinante en unidad y la consiguiente conversión en "un cuerpo organizado para la acción." Esta tarea está guiada por la idea de institución (ideé directrice): el representante queda subordinado a esta idea y el poder del gobernante sólo es realmente representativo de los gobernados cuando sea un reflejo de la idea de institución. Por otra parte, se advierte que en la teoría de Hauriou la sociedad política no emerge ni por la celebración de un contrato por parte de los ciudadanos ni por la sanción de leyes; la autoridad del poder precede a la ley, o, más precisamente, como se tiene poder, es que el representante dicta leyes. "El origen de la ley no puede fundarse en las regulaciones legales, sino que debe buscárselo en la decisión que reemplaza una situación litigiosa por un poder ordenado. ${ }^{4 "}$ (Voegelin, 2006: 65).

Se desprende de lo expuesto (del discurso de Enrique VIII, de la filosofía política de Fortescue, de las narraciones mitológicas medievales y de la obra de Hauriou, ya que son el sustento argumentativo en el que se basa la representación existencial) que para Voegelin un gobierno representativo no basta con que garantice la representación elemental-constitucional, sino, antes bien, debe ser representativo en sentido existencial, ya que, "cuando un representante no cumple con su tarea existencial, ninguna legalidad constitucional de su cargo lo salvará." (Voegelin, 2006: 67). En tiempos de crisis como los que vive Voegelin (la primera mitad del siglo XX), de desarticulación política, de desintegración espiritual, moral y de sentido, la única manera de asegurar y de salvar a la sociedad política es la representación existencial. La razón fundamental que subyace en esta representación es la búsqueda de orden ${ }^{5}$ : Voegelin cree que la época contemporánea vive en desorden, donde reina el caos y no hay valores morales y espirituales capaces de cohesionar y unificar a la sociedad. De hecho, ya algunos años antes de la publicación de NCP, en una de sus obras tempranas más importantes -Las religiones políticas- Voegelin escribía que ninguna sociedad política podía entenderse mediante la sola investigación de sus aspectos legales-formales, porque lo esencial del orden político pasa por analizar cómo los hombres se representan verdades trascendentes a través de símbolos. (Voegelin, 2000: 70).

\footnotetext{
${ }^{4}$ En este sentido, la filosofía jurídica de Carl Schmitt influyó notoriamente en Voegelin. Schmitt tampoco entiende a la representación como concepto normativo-institucional, sino que aboga por un tipo de representación existencial. Para las afinidades que existen en el concepto de representación entre Voegelin y Schmitt, véase GARCÍA RIVERA, A. (2012). "Representación y crítica de la modernidad en Voegelin y Schmitt". Revista Eikasia. Disponible en www.revistadefilosofia.org/45-04.pdf.

5 "El concepto clave sobre el cual se centran y hacen pivot los esfuerzos interpretativos de Voegelin sea justamente el de orden (...) la filosofía de Voegelin se define sintéticamente como una filosofía del orden." (Zanetti, 1989: 48).
} 
El siguiente paso que efectúa Voegelin en su teoría de la representación es profundizar el concepto de representación existencial, porque parecería que el representante de una comunidad representa otra realidad: una realidad trascendente. Voegelin afirma que "Todos los antiguos imperios, tanto en el Cercano Oriente como en el Lejano Oriente, se consideraban representantes de un orden trascendente, del orden del cosmos [...] El gobierno se convierte en la tarea de asegurar el orden de la sociedad en armonía con el orden cósmico, el territorio del imperio es una representación analógica del mundo [...] una participación simbólica del kosmion en el cosmos y el propio gobernante representa a la sociedad, dado que él representa en la tierra el poder trascendente que mantiene el orden cósmico." (Voegelin, 2006: 71-72). Así, el gobernante representa una verdad (con caracteres religiosos, ontológicos y metafísicos) que es externa a la sociedad pero que, al mismo tiempo, es constitutiva de ella. Voegelin argumenta en pos de una teoría meta-política y meta-jurídica para regular las relaciones de los hombres en sociedad: por símbolos y verdades externas es que la sociedad consigue representarse. El origen de la representación en manera alguna puede encontrarse ni en la ley ni en las instituciones mismas de la sociedad, es decir, no es inmanente.

Ahora bien, es necesario examinar cómo determinadas verdades han conseguido representarse en las sociedades occidentales. Así, ingresa el problema de la verdad en la representación. Porque, para Voegelin, los gobernantes representan verdades. Verdades en el más pleno sentido de la palabra: con elementos lógicos y epistemológicos. Así, distingue tres verdades: una verdad "cosmológica", que representaban los antiguos imperios; una verdad "antropológica”, la de la antigua Grecia; y otra "soteriológica”, la que aparece con el cristianismo. El establecimiento de las verdades representativas no fue un proceso pacífico y armónico, sino que más bien consistió en un combate existencial y político que, en muchos casos, asumió formas violentas. Y las verdades vencidas fueron excluidas y consagradas como mentiras, como noverdades, como falsas.

Resta indagar sobre un aspecto importante de la representación: qué ocurrió con ésta en la edad moderna hasta el siglo XX. En la modernidad cambia, según el filósofo alemán, la Weltschaunng, y por ende el concepto de representación se trastoca. Esto provoca la crítica que hace Voegelin a los totalitarismos del siglo XX, por lo que es consecuencia directa de la denuncia que hace del modo político del representar moderno.

La Modernidad es caracterizada por Voegelin por el abandono en la creencia en verdades trascendentes y, por tanto, por la instauración de verdades inmanentes en la sociedad. Así, la filosofía moderna secularizó e inmanentizó definitivamente la política6 ${ }^{6}$ Sostiene que, en esta época, el hombre consiguió una certeza inconmovible acerca de su lugar en la historia. Al mismo tiempo, el progreso (concepto fundamental de la Modernidad y, más aún, del Iluminismo) se constituyó en la directriz de las relaciones políticas y sociales. El hombre tiene

\footnotetext{
${ }^{6}$ Para la relación entre gnosticismo y política en la filosofía de Voegelin, véase FONTI, D. (2014). "Gnosticismo, política y religión. Aproximación crítica a una relación fundamental en Eric Voegelin”, Revista Persona y sociedad. Universidad Alberto Hurtado, Vol. XXVIII, n 32.
} 
claro sus objetivos: capitalismo económico, dominio de la naturaleza, aumento ilimitado del cientificismo. Todas estas actitudes "divinizaron" a la sociedad y abandonaron la trascendencia. La salvación del hombre se iba a lograr en la misma sociedad. A este proceso Voegelin lo llama "gnosticismo"7: "La Modernidad se define como el crecimiento del gnosticismo" (Voegelin, 2000a: 196). Esto arrastró consecuencias filosóficas y políticas extremadamente gravosas: se perdieron los lazos espirituales y morales de la sociedad; la comunidad política, sin orden alguno, sin verdades trascendentes que representar, sin unificación moral y espiritual, desembocó, nada más ni nada menos, que en los totalitarismos del siglo XX, movimientos gnósticos par excellence ${ }^{8}$. En consecuencia, la representación en la modernidad y en la época contemporánea abandonó definitivamente las verdades trascendentes como lo hacían antaño en la antigüedad y en el medioevo y se volvió inmanente. Los líderes políticos no representan más la verdad religiosa ni cósmica, sino que las ideologías políticas en las cuales se concreta la representación provienen de ideas inmanentes a la misma sociedad, tal como la sociedad sin clases en el marxismo. Para salir del gnosticismo e instaurar la nueva ciencia de la política, la solución voegeliana consiste en un retorno conceptual de la ciencia política a la sabiduría antigua y, sobre todo, a la Edad Media.

\section{Kelsen y la crítica a la representación de Voegelin}

Kelsen rechaza in totum el planteo voegeliano acerca de la representación. En cuanto a lo que Voegelin entendía como articulación política de las sociedades, Kelsen piensa que esto en la realidad de las sociedades no sucede. Los órganos estatales actúan y ejecutan decisiones políticas debido a que están obligados por un orden jurídico. El pueblo, para Kelsen, constituye sólo una unidad en el sentido jurídico, y no puede predicarse su unidad en ningún otro sentido, ora político, ora simbólico-cultural. Así, sostiene que el pueblo "Sólo puede considerársele como unidad en sentido normativo, pues la unidad del pueblo como coincidencia de los pensamientos, sentimientos y voluntades y como solidaridad de intereses, es un postulado ético-político afirmado por la ideología nacional o estatal mediante una ficción generalmente empleada y, por ende, no sometida a revisión. En definitiva, la unidad del pueblo es sólo una realidad jurídica." (Kelsen, 1977: 30-31). En cambio, cuando Voegelin se refería a la articulación política de la sociedad (el caso de la URSS), no lo hacía solamente en sentido jurídico: por el contrario, cree y aboga por la unidad cultural, simbólica, política y también jurídica de las sociedades. El soberano representa a la verdad trascendente porque el pueblo está articulado de manera integral. Para Kelsen, firmar la unidad de pueblo en otros sentidos que no sea el jurídico constituye

\footnotetext{
7 Piensa Voegelin que todo el pensamiento moderno hasta el siglo XX ha postulado el gnosticismo. Así, pensadores tan dísimiles como Hegel, Schelling, Marx, Comte, Nietzsche y Heidegger han caído en el sueño gnóstico. Corrientes tan dispares como liberalismo, marxismo, positivismo, humanismo, constituyen saberes gnósticos.

8 "Cuando los demócratas se exaltan con la igualdad y la libertad y olvidan que el dominio requiere cultivo espiritual y disciplina intelectual, puede advertirles que están de camino a la tiranía": (Voegelin, 2009: 87).
} 
ideología acrítica; una ficción ideológica con pretensiones de verdad, que, además de ser falsa y no superar ningún examen científico, es nociva para la democracia.

La representación se daba en Voegelin gracias a la articulación política de las sociedades, por tanto, el representante luego dictaba órdenes generales y contaba con la obediencia habitual de sus órdenes, representando a la sociedad de manera efectiva e indudable. Es decir: como el representante tiene poder y la sociedad está articulada, es que representa a los súbditos. Ahora bien, dice Kelsen, es aceptado sin mayores reparos que la teoría clásica del derecho y de la política, y en la práctica de los Estados, los actos de los órganos de éste son válidos si son aceptados. Esto se lo conoce como el principio de eficacia. Naturalmente, los actos estatales tienen que contar con un grado habitual de obediencia, sino el orden jurídico no sería tal. Pero a esto, aclara Kelsen, no se lo denomina representación existencial, que es como lo llama Voegelin. Es, simplemente, que el orden jurídico sea eficaz. Por lo que no hay ninguna razón, según Kelsen, para llamar a este hecho representación existencial. Escribe Kelsen que "El orden jurídico que constituye un Estado es válido sólo si es mayormente eficaz, es decir, si las personas cuyo comportamiento reglamenta lo obedecen. Pareciera que la nueva ciencia de la política presenta este principio, que la vieja ciencia jurídica y de la política daba por sentado, bajo la denominación de representación existencial." (Kelsen, 2006: 88).

Piensa Kelsen que va de suyo que la eficacia del orden jurídico nada tiene que ver con la cuestión de la representación ni con los órganos estatales, sino, antes bien, con el orden jurídico del Estado mismo. Porque no son los órganos los eficaces, "sino las normas que ellos crean y aplican de conformidad con el orden jurídico válido." (Kelsen, 2006: 90). Es decir: los actos estatales son válidos y por tanto imputables a él porque el órgano que los realice sea eficaz, sino porque el órgano estatal está determinado de antemano, previamente, por un orden jurídico relativamente eficaz.

Kelsen piensa otro tipo de origen de la representación política: es por el orden jurídico que los órganos representativos ejecutan políticas estatales: "El orden jurídico determina no sólo la función sino también al individuo que debe desempeñar tal función, al órgano." (Kelsen, 2006: 76). Voegelin, como también Carl Schmitt y su teoría del decisionismo, presuponen que es por la decisión que el gobernante tiene para tomar las disposiciones políticas y no por el orden jurídico. Para Kelsen, el instituir el orden jurídico es anterior a la representación de los órganos estatales; para Voegelin y Schmitt es a la inversa: la autoridad del poder precede a la ley. El origen de las leyes no está en la ley misma, sino que está en la decisión del poder del gobernante. Recordemos que Voegelin, cuando argumentaba en pos de la representación existencial, interpretó al institucionalismo de Hariou en este mismo sentido: como el representante tiene poder es que dicta las leyes e instituye el orden jurídico. Kelsen, por el contrario, sostiene que "La validez del orden jurídico tiene que ser supuesta de antemano si se quiere interpretar una acción humana como acto del Estado, o imputar a éste tal acción" (Kelsen, 1958: 231). Las acciones de los órganos estatales están previamente determinadas y limitadas por el orden jurídico, de 
allí que el representante está constreñido a hacer lo que dispone la ley: "La imputación de una acción humana al Estado sólo es posible cuando dicha acción se halla determinada en forma específica por un orden normativo, el jurídico" (Kelsen, 1958: 228).

La argumentación de Kelsen en cuanto a las fuentes utilizadas por Voegelin en las que apoyaba su representación existencial (repasemos: el discurso de Enrique VIII, la obra de Sir John Fortescue, la History of the Lombards de Paulus Diaconus, el institucionalismo de Hariou) es ordenada y demuestra la interpretación arbitraria y discrecional que realiza Voegelin. En primer lugar, dice Kelsen que el discurso de Enrique VIII, en términos actuales, no puede interpretárselo como representación del "pueblo", como pretende Voegelin, ya que, en esa época, el Parlamento era el "consejo común de nuestro reino", lo que quiere decir que es un órgano del Estado, porque la Carta Magna inglesa no establecía una democracia. En efecto, no se lo entendía como representante del pueblo, sino que "el rey y el Parlamento deben considerarse representantes del Parlamento. No se trata de la representación del pueblo" (Kelsen, 2006: 98). En segundo lugar, Kelsen demuestra que Fortescue no fue ningún místico y tampoco existe algo así como una "sustancia mística de la sociedad", que Voegelin ve en la intencio populi. El propósito de Fortescue fue pasar de un dominium regale a un dominium politicum regale, esto es, pasar de una monarquía absoluta a una monarquía limitada. Por otra parte, la intencio populi, el "cuerpo intangible" del reino, la "sustancia mística", no reviste caracteres místicos ni metafísicos, sino que es una categoría conceptual que compara al cuerpo del Estado con el cuerpo del hombre (como el cuerpo tiene una cabeza, la sociedad tiene un rey, y las leyes son los nervios y los tendones, etc., comparación que era usual entre los filósofos en esa época, como Hobbes o Descartes). Así, la intencio populi es sólo una estrategia de comparación y ninguna "sustancia" metafísica articuladora del pueblo, como pensaba Voegelin. Respecto a la History of the Lombards de Paulus Diaconus, los lombardos se articularon como sociedad y se dieron un representante para actuar. Actuar en esta historia implicaba la guerra. Así, cuando no había guerras los lombardos no necesitaban un rey. Así, pues, se pregunta Kelsen si un "¿líder militar autocrático es un representante del pueblo en un sentido más profundo que un gobierno democrático porque articula al pueblo para actuar, a diferencia del gobierno democrático y, así, brinda la sustancia deseada?” (Kelsen, 2006: 109). Por último, en cuanto al institucionalismo de Hariou, Kelsen afirma que la representación en el iuspublicista francés sigue la tradición democrática. La idea de representación existencial que tiene Voegelin de Hariou es nada más que la idea de organización política social, a través de órganos estatales, equilibrios de poderes y consentimientos de los ciudadanos, y así resulta la idee directrice ${ }^{9}$ (Kelsen, 2006: 113). Pero el pensador francés en ningún momento la entiende

\footnotetext{
9 “Una organización social perdura cuando debido al equilibrio entre órganos y poder, el gobierno puede subordinarse a la idee directrice que se halla dentro de la organización desde el momento de su fundación, y cuando este sistema de ideas y equilibrio de poderes se confirma, en su forma, mediante el consentimiento de los miembros de la institución así como los del medio social."
} 
Perspectivas Revista de Ciencias Sociales - ISSN 2525-1112|Año 3 No. 5 Enero-Junio 2018, pp. 131-146

como articulación de la masa del pueblo para la acción (representación existencial según Voegelin).

En cuanto a la representación de verdades trascendentes, para Kelsen es inadmisible. Postular verdades trascendentes es propio de una política anclada en bases metafísicas. Las sociedades nunca podrían representarse verdades cósmicas porque los hombres mismos han generado el orden jurídico y político: "Todo sistema de valores y especialmente un orden moral, con su idea central de justicia, es un fenómeno social y por lo tanto, diferente según la naturaleza de la sociedad en la que aparece" (Kelsen, 1956: 28). Esto, según Kelsen, es pura ideología de dominio de los poderes políticos de turno. Es una idea teológica de la sociedad que tiene como objetivo central la dominación, el deterioro y el menoscabo de las instituciones democráticas. Al contrario de lo que pensaba Voegelin, la sociedad no se autointerpreta a través de símbolos religiosos trascendentes. A lo sumo, dice Kelsen, esta autointerpretación la realiza una casta de sacerdotes o místicos iluminados en nombre de toda la sociedad. Lo absurdo de la propuesta de Voegelin es que pretende legitimar un sistema político introduciéndole a la política valores metafísicos absolutos. Pero, además, Voegelin afirmaba que el representante, cuando gobernaba, lo hacía con verdades, entiendo verdad en el sentido lógico y epistemológico. Pero esto no puede ocurrir, dice Kelsen. Las "supuestas" verdades que representaron los gobernantes que pone como ejemplos Voegelin (los antiguos imperios, Gengis Khan, los egipcios, etc.) son verdades en sentido moral y en sentido justo, es decir, la realización de valores morales y del valor justicia en la sociedad, pero no sentido científico. Así pues, Voegelin confunde ideas morales-metafísicas con ideas lógico-científicas. Precisamente el positivismo que ataca Voegelin distingue con claridad y distinción estas ideas, y separa los valores morales y las verdades científicas.

Por otra parte, piensa Kelsen que resulta paradójico el título del libro de Voegelin La nueva ciencia de la política. El ingreso de valores religiosos y metafísicos en la teoría política no tiene nada de novedoso, sino más bien constituye una antigua práctica que duró hasta bien entrada la edad moderna. Más que nueva ciencia de la política, lo que propone Voegelin es una vieja ciencia de la política: "no es exactamente una ciencia de la política nueva a la que apunta Voegelin, a pesar del título de su libro. Es una ciencia muy antigua, que se dejó de lado porque se demostró que era una seudociencia." (Kelsen, 2006: 19).

Respecto de la relación postulada por Voegelin entre el gnosticismo y la modernidad, Kelsen, a lo largo de sendas páginas, demuestra cómo la tesis sobre el gnosticismo moderno no goza de una fundamentación sólida. En primer lugar, dice Kelsen, Voegelin no hace referencia alguna a los pensadores gnósticos más importantes de la antigüedad: Cerinto, Carpócrates, Valentino, Marción, etc. Voegelin afirma que el gnosticismo comienza con Joaquín de Fiore (1145-1202), lo que no es verdad; o sea, nacería mil años después de sus orígenes históricos. Voegelin maneja las fuentes históricas de manera superficial y arbitraria, haciendo traspolaciones apresuradas entre épocas históricas. Voegelin afirmó que la salvación del sujeto en la modernidad se iba a producir en la misma tierra, y 
que en esta época histórica el sujeto conocía de manera certera el significado de la historia, dejando atrás la incertidumbre propia del cristiano. Esto no es así, sino que sucede todo lo contrario. Respondiendo a esta tesis, Kelsen escribió: "éramos de la opinión de que la esencia del cristianismo es precisamente la sensación de certidumbre que un Dios todopoderoso, absolutamente justo y al mismo tiempo infinitamente piadoso, cuya voluntad se hace en el cielo así como en la tierra, brinda al creyente. ${ }^{10 "}$ (Kelsen, 2006: 195).

Por otra parte, verdad es que en la modernidad se abandonó la creencia en verdades trascendentes: mas esto para Kelsen es la emancipación de la teología de los asuntos civiles y sociales, y la separación absoluta entre la ciencia y la religión. Este es un principio básico del positivismo sostenido por Kelsen, por lo que la modernidad y la ilustración, entonces, echaron luz y claridad para entender las relaciones humanas. Además, hacer inmanente el sentido de la historia no implica necesariamente "divinizar" a la sociedad, sino que importa el propósito de averiguar las leyes sociales y naturales. Los pensadores modernos no divinizaron la sociedad: por el contrario, Marx, Comte, Nietzsche, Freud, criticaron de manera furibunda y radical las instituciones sociales, religiosas y morales que operan en la sociedad (además de que encerrar a filósofos como Marx, Comte, Heidegger, Nietzsche, y corrientes tan dispares como el iluminismo, positivismo, humanismo, etc., como gnósticos es una interpretación simplista y absurda).

Es conocida la obstinada defensa que hizo Kelsen a lo largo de su vida de la democracia. La representación democrática (que Voegelin descalificó como elemental, casi sin valor teórico político alguno para comprender al Estado) es la mejor que pueden tener las sociedades. La forma política de representación que aboga Kelsen sigue siendo el Parlamentarismo". Escribió Kelsen que "El parlamentarismo es la única forma real en que puede plasmar la idea de la democracia dentro de la realidad social presente. Por ello, el fallo sobre el parlamentarismo es, a la vez, el fallo sobre la democracia" (Kelsen, 1977: 50). Ahora bien, en el Parlamento se establece la ficción de la representación. Es decir: que el Parlamento representa la voluntad del pueblo, y que el pueblo concreta su voluntad en este cuerpo. La ficción de la representación esconde y restringe el principio de la libertad, por lo que los detractores del sistema parlamentario aducen que la democracia es un engaño. Ahora bien, dice Kelsen, pese a que esto es cierto, el Parlamento se sigue justificando: es "la transacción necesaria” entre la idea de libertad política y el principio de la mayoría.

10 Contrariamente a lo que cree Voegelin, muchos autores demostraron que la Modernidad constituyó para el sujeto la pérdida en los valores firmes y dadores de sentido del cristianismo; el sujeto se encuentra lleno de incertidumbres, arrojado y perdido, sin saber de dónde viene y adónde va. En este sentido, Heidegger hablaba de la imposibilidad de una filosofía cristiana: "una filosofía cristiana es un hierro de madera y un malentendido", porque la primer y fundamental pregunta del verdadero filosofar es ¿Porqué el ente y no más bien la nada?, y para esta pregunta el cristiano tiene una respuesta inequívoca: el ente es creado por Dios y al final del camino del hombre está Dios: (Heidegger, 2003: 16-17).

11 Para ahondar sobre la representación parlamentaria en el pensamiento de Kelsen, véase GARZÓN VALDES, E. (1989). “Representación y Democracia”, Revista Doxa, № 6. Disponible en www.biblioteca.org.ar/libros/141760.pdf. 
Además, y más allá de las razones de orden histórico que avalan al Parlamento como órgano representativo (ya que la lucha del parlamentarismo en las Revoluciones Inglesa, Francesa y Norteamericana fue la lucha por la libertad en detrimento de las monarquías) la necesidad de la representación parlamentaria se justifica para Kelsen por varias razones: primero, como herramienta técnico social para la organización del Estado; segundo, porque ve que en las sociedades con un considerable progreso material y técnico organizacional existen, con distintas variantes, alguna especie de Parlamento o Asamblea colegiada (hasta en las autocracias o monarquías existe alguna asamblea de personas para la ejecución de las políticas estatales, ya sea como órgano productor de las leyes o como órgano consultivo), por lo que esto es como "una ley de construcción de los organismos sociales." (Kelsen, 1977: 56). Por otra parte, el Parlamento es una "exigencia" para conformar la voluntad estatal, que, en la práctica política de las sociedades, se da a través de la transacción de los grupos humanos de poder (partidos políticos) que dan nacimiento a un conjunto de normas obligatorias para la comunidad. Además, se pregunta Kelsen, ¿qué sucedería si el Parlamento se elimina de las democracias?

Ahora bien, Kelsen no desconoce las limitaciones formales y materiales que asedian la práctica parlamentaria; mas propone como soluciones políticojurídicas concretas la "intensificación" de los elementos democráticos en el Parlamento: referéndum popular, plebiscitos, la abolición de las inmunidades de los legisladores (resabio de privilegios heredados de los siglos XVII y XVIII), la consulta popular, etc. Estas son algunas de las soluciones a los problemas de representación en el Parlamento ${ }^{12}$.

\section{Consideraciones finales}

Luego de analizar las concepciones de representación que tuvieron Voegelin y Kelsen y que se vieron reflejadas principalmente en el interesante debate intelectual que mantuvieron a principios de los años 50, es preciso hacer una especie de balance para poder ver qué tesis político-jurídicas nos sirven a nosotros para pensar la representación en la actualidad.

Quizás lo más destacable del pensamiento de Voegelin sea el haber denunciado tenazmente los totalitarismos del siglo XX -y se vio forzado al exilio por el nacionalsocialismo- y diagnosticar con agudas observaciones los males sociales que padecían las sociedades occidentales y cómo el mundo iba camino a la catástrofe. Asimismo, es cierto que el ideal de sujeto moderno se apoderó de la naturaleza, dominó el mundo entero sin límites, y construyó un ideal de hombre con rasgos individualistas exacerbados. Por otra parte, y como hizo su par Carl Schmitt, Voegelin supo ver cómo los símbolos y los mitos juegan un papel fundamental en las sociedades políticas y cómo operan de manera inconsciente, pero efectiva y real. Ahora bien, la crítica y la denuncia que hace Voegelin son, indudablemente, mejores que los remedios propuestos. Allí, entiendo, se encuentra la riqueza del pensamiento voegeliano.

${ }^{12}$ En el capítulo IV de Esencia y valor de la democracia Kelsen desarrolla esta tesis. 
Mas las soluciones políticas propuestas por Voegelin son problemáticas: la representación existencial, el gobernante como portador y ejecutor de verdades trascendentes, la búsqueda de un orden espiritual, el retorno a la ciencia política fundada en valores absolutos teniendo como bases Platón, Agustín y Tomás, son tesis que van en contra de los regímenes democráticos, pluralistas, relativistas, con fundamentos políticos inmanentes y que pretenden asegurar los derechos humanos individuales. El buen orden político no se define por su espiritualidad ni sus verdades trascendentes, sino, antes bien, y como pensaba Kelsen, por el diseño y buen funcionamiento de sus instituciones democráticas. Contra el gobierno de unas élites iluminadas, es preciso anteponer, como sostiene el filósofo francés Jacques Ranciere, una noción de democracia definida como "una superioridad que no se basa en más principio que la ausencia misma de superioridad. Democracia quiere decir, ante todo, esto: un gobierno arcaico, fundado nada más que en la inexistencia de título alguno para gobernar." (Ranciere, 2007: 63). La democracia no reconoce títulos filiatorios, honores, capacidades especiales: cualquiera puede gobernar y ser gobernado en cualquier momento. El azar y la aleatoriedad, en este sentido, son la esencia de la democracia. La democracia es, al decir de Ranciere (y creo que Kelsen compartiría esta tesis), "el poder propio de los que no tienen más título para gobernar que para ser gobernados." (Ranciere, 2007: 71).

La mejor forma de pensar la representación política es en términos inmanentes. Las sociedades son las que instituyen el orden jurídico y político sin ninguna referencia a entes trascendentes o verdades exteriores a ella. La trascendencia, como piensa Kelsen, en materia política, es sumamente riesgosa; es, sin más, metafísica, y por tanto seudociencia. La metafísica nada tiene que hacer en las instituciones políticas de la democracia. Mas grave aún: la introducción de valores absolutos en política es una vía idónea para recaer en la autocracia y en los regímenes totalitarios. Para Kelsen, y fiel a su relativismo epistemológico, los valores supremos (tales como la justicia, el bien) jamás pueden ser justificados de manera absoluta. Acaso hasta la democracia misma no puede hacerlo: "La democracia, como forma de gobierno, puede justificarse relativa pero no absolutamente." (Kelsen, 1956: 35). Lo que ocurre, dice Kelsen siguiendo a Hume ${ }^{13}$, es que la conciencia psíquica de los hombres tiene una necesidad psicológica inevitable de postular y creer en absolutos.

La inmanencia -inmaneo significa permanecer en- en la teoría política contemporánea es aceptada casi sin discusión y la crítica de las instituciones políticas se construye a partir de allí. En democracia, no hay lugar para los valores absolutos tal como los pensaba Voegelin: orden, espíritu, justicia, representación de verdades. Kelsen observaba que hay una íntima relación entre democracia y relativismo. Es el sistema epistemológico que más le conviene a la democracia. "Esta pugna de concepciones metafísicas es paralela a la antítesis de actitudes políticas: a la concepción metafísico-absolutista del mundo se ordena la actitud autocrática, así como la democracia corresponde a la concepción científica del universo, al relativismo crítico." (Kelsen, 1977: 154).

13 Véase HUME, D. (2010). Investigación sobre el entendimiento humano. Buenos Aires: Losada. 
Es decir: valores absolutos: autocracia; valores relativos: democracia, afirma Kelsen ${ }^{14}$.

El orden jurídico-político de las sociedades debe estar dado exclusivamente por leyes e instituciones políticas ajenas a la religión y a la metafísica. Esto no implica que sea neutral: por el contrario, a todo orden jurídico le subyace una ideología, valores morales, preceptos políticos: "La teoría política y la experiencia muestran que, según fuere la época y el lugar, existen ideologías socialmente válidas que legitiman, también durante un tiempo y un espacio, a los órganos estatales encargados de establecer y asegurar el derecho positivo." (Barbará, 2008: 15). Pero eso no implica sostener que los representantes reflejen verdades cósmicas que provienen del exterior. La religión y la política son cosas totalmente distintas y es conveniente mantenerlas separadas. Ya Pascal hace más de cuatro siglos nos alertaba diciendo que "nunca hacen el mal los hombres tan completa y alegremente como cuando lo hacen por convicción religiosa." Un régimen político que represente verdades religiosas es muy posible que de a lugar a la subordinación de los derechos y los intereses individuales en pos de un "supremo" bien de la sociedad, que, en su caso, el gobernante representa. Por tanto, obligar a los ciudadanos a adoptar actitudes comunitarias sacrificiales para el balanceo entre los derechos individuales y los intereses colectivos es antidemocrático y contrario a los principios básicos del Estado de Derecho.

Por otra parte, la representación democrática es la forma más proclive para que los ciudadanos expongan sus demandas de derechos y consigan satisfacción sobre los mismos. Es en las instituciones democráticas donde se desarrollan los consensos y los conflictos políticos, descartando todo tipo de trascendencia y, sobre todo, de llegar a una verdad, como lo hacía Voegelin. La democracia es, pues, la lucha y el juego de distintas verdades, siempre relativas y cambiantes. Es el primado de la multiplicidad política contra la unidad. Richard Rorty pensaba que la política consiste justamente en abandonar la fundamentación de la misma en argumentos trascendentales y aceptarla como un ejercicio que, a partir del diálogo intercultural, permite crear instituciones y formas diversas de relación social. Para esto es necesario abandonar toda metafísica y asumir la contingencia absoluta e inherente a la política.

Recibido: 22/02/2018

Aceptado: 25/05/2018

\section{Bibliografía}

\footnotetext{
14“Si desaparece la creencia en la posibilidad de una ciencia libre de intereses del poder político $y$, por tanto, digna de la libertad, o si el ideal de la objetividad del conocimiento cede el puesto a otros ideales, se inicia el viraje hacia una actitud espiritual favorable a la autocracia." (Kelsen, 1977: 143).
} 
BARBARÁ, J., (2008). Estado de derecho y autonomía de la voluntad. Córdoba: Advocatus.

CASANOVA, C., (1997). Verdad escatológica y acción intramundana. La teoría política de Eric Voegelin. Navarra: Eunsa.

GARCÍA RIVERA, A., (2012). "Representación y crítica de la modernidad en Voegelin y Schmitt". Revista Eikasia. Disponible en www.revistadefilosofia.org/45-04.pdf.

GARZÓN VALDÉS, E., (1989). “Representación y Democracia”, Revista Doxa, № 6. Disponible en www.biblioteca.org.ar/libros/141760.pdf.

FONTI, D., (2014). "Gnosticismo, política y religión. Aproximación crítica a una relación fundamental en Eric Voegelin". Revista Persona y sociedad, Universidad Alberto Hurtado, Vol. XXVIII, $\mathrm{n}^{\circ} 3$.

HEIDEGGER, M., (2003). Introducción a la metafísica. Barcelona: Gedisa.

HUME, D. (2010). Investigación sobre el entendimiento humano. Buenos Aires: Losada.

KELSEN, H. (1956). ¿Qué es la justicia? Córdoba: Universidad Nacional de Córdoba.

KELSEN, H. (1958). Teoría general del estado y del derecho. México D.F.: Universidad Nacional Autónoma de México.

KELSEN, H. (1977). Esencia y valor de la democracia. Barcelona: Editorial Labor.

KELSEN, H. (2006). ¿Una nueva ciencia de la política? Réplica a Eric Voegelin, Buenos Aires: Katz.

MÉTALL, R. (1976). Hans Kelsen. Vida y Obra. México D.F.: Universidad Nacional Autónoma de México.

RANCIERE, J. (2007). El odio a la democracia. Buenos Aires: Amorrortu.

RORTY, R. (1989). La filosofía y el espejo de la naturaleza. Madrid: Cátedra.

SANDOZ, E. (1981). The Voegelinian Revolution: A biographical introduction. Baton Rouge: Louisiana State University Press.

VOEGELIN, E. (2000a). Modernity without reistraint. Columbia: University of Missouri Press. 
VOEGELIN, E. (2000b) The political religions. Columbia: University of Missouri. VOEGELIN, E. (2006). La nueva ciencia de la política. Buenos Aires: Katz. VOEGELIN, E. (2009). El asesinato de Dios y otros escritos políticos. Buenos Aires: Hydra.

ZANETTI, G. (1989). La trascendenza e l'ordine. Saggio su Eric Voegelin. Bologna: Clueb. 